curved undulated or folded plates, in which the distances are variable, and consequently defective.
In the Montaud accumulator, the weight is simply For the notion "so much capacity and so much yield
pron per kilo," Montaud substitutes the notion "so much capacity or yield per square meter, the weight not being taken into consideration." they have from 1 to 12 square meters of surface, and the number corresponding to the surface indicates its pacity, and its manner of discharge. meter of active surface can receive a charging current the intensity of 20 ampere

face of 10 square meters, a charging current of 100 amperes, and on discharging a current of 200 amperes. weighs about 11 kilos. As both surfaces of the lead 10 therefore requires $55 \mathrm{kil}$ red. of useful lead. It will be seen that to increase the thickness of the
sheet of lead merely augments the duration of the accumulator, without affecting its capacity or its manne of charging and discharging.

ware, ware, glass, or ebonite, or in boxes of pitch pine, boxes lead. Nos. 5 to

The box is supported on feet of porcelain of the shape of a mushroom. If a drop of water falls upon earth, since, falling upon the broad part of the mushroom, it will glide off withont running along the foot, which serves as the stalk of the mushroom. A slip of
glass is placed under each foot; the part which supglass is placed under each foot; the part which sup-
ports the mushroom is covered with an insulating
varnish, which prevents the formation of climbing salts and preserves the screws froun rust of climbing salt insulating varnish is applied under the head of the mushroom. ator wenotice, first, its longevity.

Dr. D'Arsonval points out that the accumulators of type as regards duration, and that the most striking The inventor has in his possession positive plates, five to six years old, completely peroxidized, though there remains in the interior a thin core of metallic hesion of the peroxide is such that to detach it, it must be beaten with a hammer upon an anvil.

The nield much points, $i$. $e$., the rapidity of charge in proportion to its surface ; its small weight in comparson with its yield : and its capacity, which for an 作 In his experiments in September, 1885, Dr. D'Arsonval
obtained with an accumulator of 2 square meters of

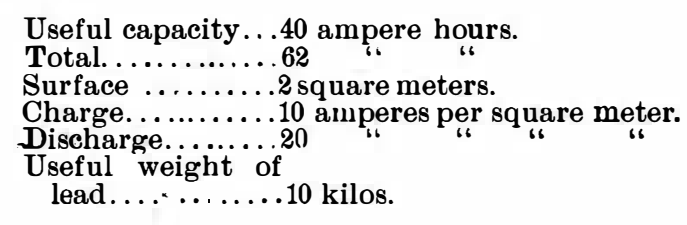

Representing a total capacity of 6 ampere hours per capacity of 31 ampere hours per square meter and useful capacity of 20 ampere hours per square meter. has greatly improved these figures, which will certainly The total capacity of an accumulator having exactly
Thering $13 /$ meters of surface has become 87 ampere hours, of surface, would give the following results:

Useful weight of lead per

square meter.. ..........51/2 kilos.

per kilo.................. $9 \cdot 1$ ampere hours.
T'otal capacity per square

meter.................. 50
Useful . capacity per kilo. of

useful lead $\ldots \ldots \ldots \ldots \ldots$
Useful capacity per square

Current of charge per square
meter..................10 amperes.

Current of charge per kilo. of
useful lead ...............

Current of discharge per

Current of discharge per kilo.

of useful lead.............. 4.56

The next advantage of the Montaud accumulator is the ease with which it can be taken out of its box and repaired without special tools and experience. terfered with the use of accumulators. In case of accidents, several kinds of which are possible, it is found accumulator is much less liable to accidents, on accoun if any accident happens, the repairs are simple and

Lastly, the stout framework secures the apparatus from any accident due to a disproportionate charge or already described solve this problem.

On September 8, 1885, Dr. D'Arsonval, Professor at
the College of France, wrote as follows: "The Montaud accumulator is of the Plante type, and is ex view. The wooden combs prevent the plates from com ing in mutual contact, and give the apparatus great

To give 1 square of formation is ingenious and rapid. there is required only a quarter of an hour's treatment \section{o obtain the}

"The entire experiments have been effected with , which has a surface of 2 square meters. This apparaits total capacity, and, as in the Plante, this capacity constantly increases with use. The normal rule for discharge double this quantity. This apparatus has
always given me on discharging 40 amperes at the always given me on discharging 40 amperes at the
.M.F., of 1.85 volts during 60 or 65 minutes. The
charge is effected in two hours up to 20 amperes, withut any appreciable loss of electricity.

"Thevity and energy, or, rather, rapid yield pator are From both points of view accumulators of the Plante uperior to those of the Faure type.
"My opinion, therefore, is that the Montaud accum ator is very practical, that it is a great improvement on the Plante type, and that it can compete successfully with the other systems in use."
nationale de l'Electricite; Elec. Review.

NATURAL SOLUTIONS OF CINNABAR, GOLD AND ASSOCIATED SULPHIDES. By GEORGE F. BECKER.

Is the course of investigations on the geology of the quicksilver deposits of the Pacific slope I have taken
up the question of the state of combination in which quicksilver is dissolved in natural waters. Pyrite or marcasite alnost invariably accompanies cinnabar,
gold is known to be associated with cinnabar in a con siderable number of cases, copper sulphides or sulpho-
salts are also not infrequent in quicksilver mines, and sulphides of arsenic and antimony are known to occur
in a similar association. Zincblende too has been in a similar association. Zincblende too has been stances has been incidentally examined. In perform-
ing the experiments I had the assistance of Dr. W. $\mathbf{H}$. Melville, who also made all the quantitative analyse
involved. The results obtained seemed interesting enough to justify their publication, in an abbreviated
form, in advance of the monograph of which they will form a part. They also possess some value from a rs of this journal who are not geologists.

gold, probably in the metallic state; sulplides of gold, probably in the metallic state; sulplides of arsenic, antimony, and mercury; sulphides or sulpho-
salts of silver, lead, copper, and zinc; iron oxide and
possibly also iron sulphides ; manganese, nickel, and The sulphides which are most abundant in the deposits are found in solution in the water itself, while
the remaining metallic compounds occur in deposits the remaining metallic compounds occur in deposits
from springs now active, or which have been active within a few years. These springs are thus actually
adding to the ore deposit of the locality, which has been worked for quicksilver in former years, and would again be exploited were the price of this metal to re-
turn to the figure at which it stood a few years sine. At Sulphur Bank also there is reason to suppose that
ore deposition is still in progress, though the ore deposition is still in progress, though the oppor-
tunities for determining this point are greatly inferior
to those presented at Steamboat Springs. The waters to those presented at Steamboat Springs. The water tain sodium carbonate, sodium chloride, sulphur in one or more forms, and borax as pringe at Steamboat
and both are extremely hot, those at
Springs in some cases reaching the boiling point. In attempting to determine in what forms the ores enumerated can be held in solution in such waters, it is mani-
festly expedient to begin by studying the simplest festly expedient to begin by studying the simplest
possible solutions of the sulphides and particularly of
cinnabar * Solubility of $\mathrm{HgS}$ in mixtures of $\mathrm{Na}_{2} \mathrm{~S}$ and $\mathrm{NaOH}$.A series of experiments were made in my laboratory with a view of testing therelativeeffect of the quantity of somercuricsulphide which a given mixture of the solvent would take up. It is almost impossible to make experi-
ments of this kind with the same accuracy which can * Previous Inwestigation.-The solubility of mercuric sulphide in al-
kaline componuds containing sulphur has long ben recognized by ex-
perimental and industrial chemists. This fact is the foundation of the

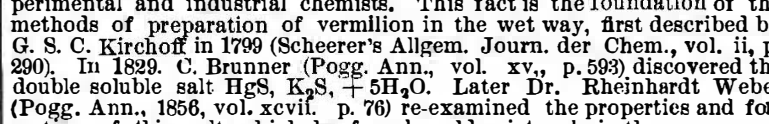

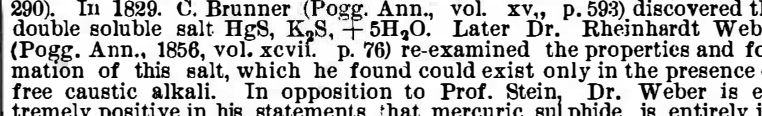

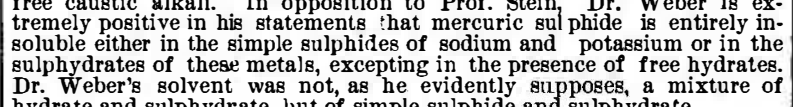

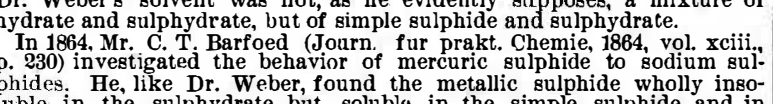
phides He, like Dr. Weber, found the metallic sulphide wholly inso-
luble in the sulphydrate, but soluble in the simple sulphide, and in
mixtures of the latter either with the sulphydrate or with the hydrate.
He insists that the necessary and sufficient condition for the solubility of

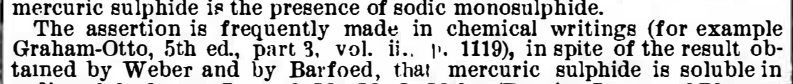

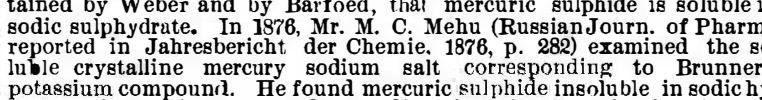

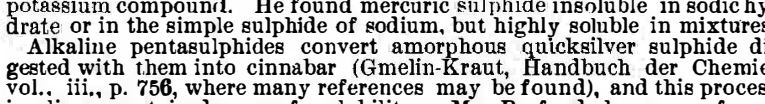

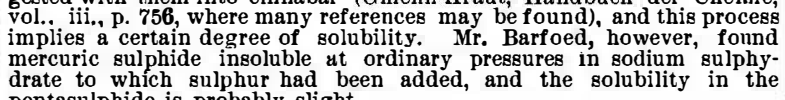

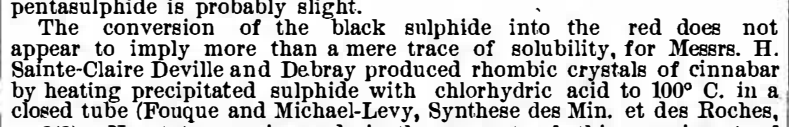

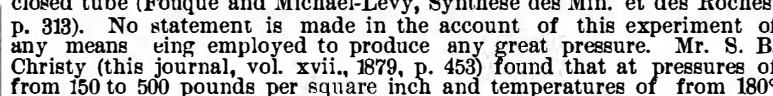

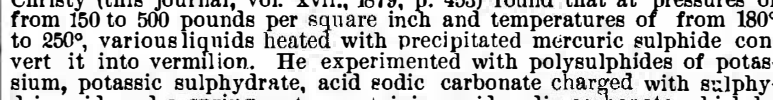

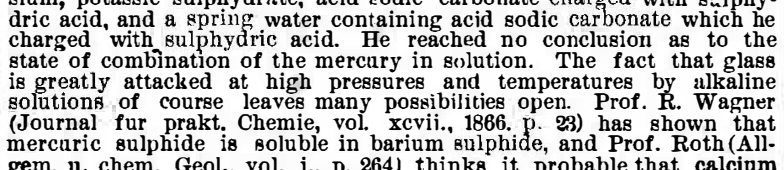

easily be attained in precipitations, because, if one or moredrops of either fluid reagent is added to a mass conmenstruum, it is not practicable to say how long a become saturated. Approximate results are, however, readily obtained, and these appear in the present case It was found that, provided a small quantity of free hydrate exists in the mixture, the solubility of $\mathrm{HgS}$ depends solely upon the quantity of $\mathrm{Na}_{2} \mathrm{~S}$ in the solu-
tion. The average of fourteen experiments made with varying proportions of sodic hydrate gives $1 \mathrm{HgS}$ to slight excess in the quantity of solvent employed is to mercuric sulphide and sodic sulphide in the proportion of two molecules of the latter to one of the former, and
adding a few drops of caustic soda. A mere trace of
mercuric sulphide remained undissolved, and this commercuric sulphide remained undissolved, and this com-
pletely disappeared on the addition of a single drop of completed the solution.

Chemists of course regard cases of solution that under discussion as due to the genesis of soluble double salts, which are formed according to ordinary laws of composition. The above experiments show
that this soluble double salt can be represented only in the formula $\mathrm{HgS}, 2 \mathrm{Na}_{2} \mathrm{~S}$. The soluble mixture given
by Mehu answers to $\mathrm{HgS}+2 \cdot 07 \mathrm{Na}_{2} \mathrm{~S}$, and is thus, so far as it goes, confirmatory of the above experiments.
Solubility of $\mathrm{HgS}$ in $\mathrm{Na}_{2} \mathrm{~S}$. - The most carefully prepared solutions of sodium sulphide dissolve mercuric pared solutions of sodium sulphide dissolve mercuric
sulphide freely. This statement is directly contrary to that which some of the chemists referred to have made, duced for it depended simply upon bringing solutions
of sodic sulphide into contact with mercuric sulphide. of sodic sulphide into contact with mercuric sulphide.
For it is impossible to make certain that there is no For it is impossible to make certain that there is no tion of sodic sulphide, however closely its analysis may
correspond to its theoretical composition. If, however, a solution of sodic sulphide containing sodic ually converted into sodic sulphydrate, and passes through a point at which the only compound present
is the monosulphide. If mercuric sulphide is dissolved in a mixture of sodic sulphide and caustic soda, and th 9 clear filtrate is treated with hydrogen sulphide, very little free caustic alkali is left, and is continuously
very precipitated until the entire amount of sodium present precipitated until the entire amount of sodium present
tions of $\mathrm{Na}_{2} \mathrm{~S}$ which we have been able to preparations of $\mathrm{Na}_{2} \mathrm{~S}$ which we have been able to make dis-
solve mercuric sulphide less freely than nixtures of
sodic sulphide and sulphydrate. Different preparasodic sulphide and sulphydrate. Different prepara-
tions, however, shown by most careful analysis to cortions, however, shown by most careful analysis to cor-
respond very accurately to the formula $\mathrm{Na}_{2} \mathrm{~S}$, give minute variation from results, possibly indicating a minute variation from absolute purity. It does not seem a priori improbable that the soluble salt when and one of our preparations gave alinost exactly this
result. It may also be that mixtures of $\mathrm{HgS}, 2 \mathrm{Na}$, and $\mathrm{HgS}, 4 \mathrm{Na} \mathrm{s}_{3} \mathrm{~S}$ are formed in proportions varying Insolubility of $\mathrm{HgS}$ in cold NaHS.- Repeated experiments and analyses undertaken during this investiinsoluble in sodium sulphydrate at ordinary temperatures, and that any preparation of this compound which will dissolve a trace of mercuric sulphide can be shown by analysis to fall short of complete saturation. sulphide are required to completely saturate even a
small amount of caustic soda with sulphur. As already mentioned, both Weber and Barfoed were aware of phydrate at ordinary temperatures. It will be seen later that the behavior of these compounds varies with the temperature. If mercuric sulphide is left in contact with cold sodic sulphydrate for twenty-four hours,
just a trace of mercury goes into solution. This is due to the spontaneous loss of hydrogen sulphide which he sulphydrate is well known to undergo.
The absolute want of power of a preparation of sodic sulphydrate to dissolve a trace of mercuric sulphide is perhaps the best known test of its freedom from the alkaline monosulphide. This test does not show the quently found mercuric sulphide totally insoluble in solutions of sodic sulphydrate which possessed a yellow
color, and which were proved by analysis to contain an color, and which were proved by analysis to contain an
excess of sulphur. This corresponds to Barfoed's observation. The occurrence of alkaline polysulphides in so im probable that I have undertaken no investigations of the condic sulphide.
curic

Solubility of $\mathrm{HgS}$ in mixtures, of $\mathrm{Na}_{2} \mathrm{~S}$ ard $\mathrm{NaHS}$ For the purpose of determining the character of soluphide and sulphydrate, clear solutions of mercuric sul
phide in sodium sulphide and sodium hydrate were made, all the reagents being carefully prepared for through the solution until a large permanent precipithrough the solution until a large permanent precipifiltered, and of course the filtrate represented an absoture of sodic sulphide and sulphydrate. A portion of
this solution was analyzed. The remainder was treated further with hydrogen sulphide, the precipitation be-
ing arrested before the separation of nercuric sulphide was completed; and the second filtrate, representing a second saturated solution of the metallic sulphide in a containing much less mercuric sulphide, was also analyzed.
These analyses, which formed the conclusion of a tedious series of experinents, show beyond any reasonis soluble in the presence of $\mathrm{Na}_{2} \mathrm{~S}_{1} \mathrm{H}_{2} \mathrm{~S}$, and which is de-
composed by hydrogen sulphide in the presence of the
sulphydrate by the reaction,

$\mathrm{HgS}, 4 \mathrm{Na}_{2} \mathrm{~S}+4 \mathrm{H}_{2} \mathrm{~S}=\mathrm{HgS}+4 \mathrm{Na}_{3} \mathrm{~S}, \mathrm{H}_{2} \mathrm{~S}$. Conclusion from the experiments.-It appears from
the above that there are at least three double salts of 
the form $\mathrm{HgS}, n \mathrm{Na}_{2} \mathrm{~S}$, where $n$ may be either 1,2 , or 4 , and, judging from the analogy of the potassium comgroup where $n$ is $1 / 2$. 'The possibility of a case where $n$
is 3 has also been adverted to. Thus readily enters into combination with sodic sulphide in various proportions, while all the best known soluble
compounds of mercuric sulphide and sodium have the same general formula. The presence of carbonates of
the alkalies is also known, especially from Mehu's re the alkalies is also known, especially from Mehu's re-
sults, to be compatible with the existence of these
compounds. The question therefore arises whether compounds. The question therefore arises whether
such double sulphides may not exist in natural waters. question resolves itself into two. It is to be considered whether $\mathrm{Na}_{2} \mathrm{~S}$ may exist in natural waters as such. In
that case such waters must dissolve mercuric sulphide. It is also possible that alkaline monosulphides cannot exist as such in these waters, but that the affinity of
sodic sulphide and mercuric sulphide is sufficient to phide, and that this compound will form when mercu政 of interest to chemical geology.
A train of thermo-chemical reasoning, upon which it is not necessary to enter here, makes it extremely
probable that, at temperatures exceeding $80^{\circ}$, a certain probable that, at temperatures exceeding 80 , a certain
amount of sodic sulphide may form by the decompo-
sition of neutral sodium carbonate and sodium sulphydrate in the presence of acid sodium carbonate. The temperature indicated is also such as it would be if the sodic sulphide actually formed; but a full and suffieient proof of the reaction which theory indicates as
probable seems very difficult, and has not yet been accomplished.

It is certain, however, that a tendency exists to the
formation of sodium sulphide under these conditions. formation of sodium sulphide under these conditions. it can be proved experimentally that sodic sulphide is a mixture of the two carbonates and the sulphydrate
dissolves mercuric sulphide freely without a sensible evolution of gas. If the solvent does not contain sodic
sulphide, it must contain the sulphydrate. Hence it sulphide, it must contain the sulphydrate. Hence it
becomes important to ascertain the behavior of mercuric sulphide to sodic sulphydrate at moderately ele vated temperatures.
While sodic sulphydrate will not dissolve a trace of mercuric sulphide at ordinary temperatures, if merdrate which stands upon the water-bath, hydrogen sulphide is evolved and mercuric sulphide goes into
solution. The fact that hyarogen sulphide is evolved demonstrates that sodic sulphide must be formed. Cooling does not reprecipitate the mercuric sulphide,
and the compound dissolved is therefore of the form $\mathrm{HgS}, n \mathrm{Na}_{2} \mathrm{~S}$. solutions of the alkaline sulphydrates at ordinary pressures has, so far as I know, never been explicitly stated, that, in consequence of this observation, the general line sulphydrates has remained in chemical literature The preparation in which I or iginally observed this already been removed by precipitation with hydrosulalready been removed by precipitation with hydrosul-
phuric acid. The experinent was afterward repeated
by Dr. Melville with several preparations of sulphyby Dr. Melville with several preparations of sulphy-
drate which had been accurately analyzed and had
been tested in numerous ways. Now, in a mixture of been tested in numerous ways. Now, in a mixture of the carbonates and sulphides of sodium at the tempersulphydrate is present, or, more probably, both coexist.
If, then, mercuric sulphide is added to such a solution, either sodic sulphide combines directly with mercuric sulphide, or sodic sulphydrate is decomposed by mercuric sulphide setting free hydrogen sulphide, which bonate. Hence in any case the salt dissolved in the mixture must be of the form $\mathrm{HgS}, n \mathrm{Na}_{2} \mathrm{~S}$.

Effects of dilution.-Laboratory experiments are
usually made with solutions which are much more entrated than those found in nature. Hence the portant dition on solutions of $\mathrm{HgS}, n \mathrm{Na}_{2} \mathrm{~S}$ are immixture of sodium monosulphide and sodium hydrate, water precipitates mercuric sulphide. some curious phenomena to be described hereafter, is
clear. It is known through the investigations of
Messrs. Kolbe, Thomsen, and others, that while in moderately concentrated solutions

$\mathrm{NaHS}+\mathrm{NaHO}=\mathrm{Na} \mathrm{a}_{2} \mathrm{~S}+\mathrm{H}_{2} \mathrm{O}$,

this reaction is partially reversed on dilution ; or that, posed by water, the proportion of the sulphide undergoing this decomposition increasing gradually with the $n \mathrm{Na}_{2} \mathrm{~S}$ is effected in the same way, more and more of drate as the dilution increases, probably without an limit. Since mercuric sulphide decomposes hot sodic evidently be less than in cold ones.
Brunner* found that dilution of solutions of his salt precipitated a black mass in which, on examination The quantity of mercury was extremely small, so that indeed to the composition expressed by the formula HgS. Gmelin-Kraut $\nmid$ appear to have some independmercury is precipitated in diluted solutions, of course
sulphur is liberated: and, as shown above, sodium sulphur is liberated: and, as shown above, sodium
hydrate must also be present. Now, when these two substances are brought in contact, sodic hyposulphite
forws. Accordingly, Brunner found hyposulphite in the solution forty years before the decomposition of sodic sulphide in dilute solution had been elueidated
As Brunner experimented with $\mathrm{HgS}$, Na $\mathrm{Na}_{2}$, I thought

$$
\begin{aligned}
& \text { * Loc. cit. } \\
& \text { +L. c., vol. iii, p. } 861 .
\end{aligned}
$$

concentrated perfectly clear solution of freshly pre-
pared mercuric sulphide in a mixture of sodic sulphyrate and caustic soda, containing very little of the
atter, was suddenly diluted with cold water to 200 times its volume and rapidly filtered. Minute globules the filter. On digestion (after thorough washingr) with very dilute nitric acid, a solution was obtained from
which sulphydric acid precipitated black sulphide. The decomposition thus appears to be the same in each Influence of foreign substances. - The fact that so$\mathrm{Na}_{2} \mathrm{~S}$ is evident both from Mehu's result and from our own. Experiments show that borax solutions precipi rogressive, like that accompanying dilution, but to reach a sharp limit. beyond which further additions
produce no effect. A large amount of borax added to a concentrated solution of $\mathrm{Na}_{2} \mathrm{~S}$ and $\mathrm{NaHS}$ does not magine reactions by which borax may precipitate portion of the mercuric sulphide. But the behavior of
solutions of borax to sulphydric acid and to alkaline
sulphides is very peculiar, and, so far as I am aware, has not.been thoroughly in vestigated.* ${ }^{*}$ Very concen-
rated solutions of sodium chloride do not precipitate mercuric sulphide from strong solutions in mixtures of mercuric sulphide from strong solutions in mixtures of
odic sulphydrate, and they even appear to delay, but Solubility of $\mathrm{Fe}_{2} \mathrm{~S}$. - The sulphide wh

uently associated with that of mercury is most frequently associated whe that of mercury is pyrite or
qarcasite. Indeed, these minerals in greater or smaller
quantities are to be found in nearly every hand specimen of ore, and occur very abundantly in most quicksilver mines. On making the experiment I found that pyrite, marcasite, or precipitated ferrous sulphide when quantity, while the solution changed color. The
filtrates gave strong reactions for iron.
Pyrite dissolves in cold solutions of sodium sulphide without any evolution of gas. The solvent power
seems to increase with the temperature. Pyrite, lik cinnabar, appears totally insoluble in cold sodium sul-
phydrate, and, like cinnabar, pyrite dissolves to some phydrate, and, like cinnabar, pyrite dissolves to some also soluble in solutions of sodium carbonate partially saturated with sulphydric acid, both hot and cold Marcasite is more easily soluble than pyrite and the
Marted her for the sake brevity imple precipitated sulphide goes into solution most readily of all. I think there can be no doubt that
pyrite and marcasite form double salts with sodium ulphide entirely analogous to the soluble coin pounds than pyrite, just as metacinnabarite is more susceptible the action of reagents than cinnabar.
Solubility of Gold. - The association of gold and pyrite is world wide. According to Gahn t there is no pyrite which does not yield traces of gold when careperience, for extremely careful tests of some pyrite in gold. Gold is associated with quicksilver, however, at California, at the Manzanita mine, at the Reddington
mine, and some other localities both in California and in foreign countries. From these facts I concluded that gold should be soluble in sodic sulphide. On warming
chemically pure, precipitated gold dust with a solution of sodic sulphide, the glittering scales of gold gradually
disappeared. The filtrate, after proper manipulation, disappeared. The filtrate, after proper manipulatio
yielded a purple precipitate with phosphorous acid.

A solution containing 843 parts of $\mathrm{Na}_{2} \mathrm{~S}$ (by weight)
dissolves one part of gold at the ordinary temperature of the atmosphere. Gold also dissolves at ordinary temperatures in sodic sulphydrate and in solutions of
sodic carbonate partially saturated with sulphydric
acid. The solubility appears to be increased and faciliSolubility of other sulphides.-Cupric sulphide dis-
ated by heat. solves less readily than pyrite in sodic sulphide and in
mixtures of the sodic carbonates and sodic sulphydrate. mixtures of the sodic carbonates and sodic sulphydrate.
Unlike pyrite, it also dissolves in thoroughly saturated
sodic sulphydrate. Zinc sulphide is also soluble, and sodic sulphydrate. Zine sulphide is also soluble, and
behaves much as pyrite does. Quantitative determinations of the solubility of these substances have also been made. The solubility of the sulphides of arsenic and of course well known. In the presence of neutral sodic in sodic sulphydrate without the evolution of gas, be-
cause the sulphydric acid set free reacts upon the carNatural solutions and precipitations.--The foregoing experiments show there is a series of compounds of mercury of the form HgS, $n \mathrm{Na}$ S, one or the other of which is soluble in aqueous solutions of caustic soda,
sodic sulphydrate or sodic sulphide, and apparently also
in pure water, at various temperatures. These soluin pure water, at various temperatures. These solu-
tions subsist, or subsist to some extent, in the presence of sodic carbonates, borates, and chlorides. There is Springs contain mercury in this form, and that th waters of Sulphur Bank have contained mercury in th same form, if indeed they do not still carry it in same form, if indeed they do not still carry it in
solution. Bisulphide of iron, gold and zincblende form
double sulphides with sodium, which appear to be analogous to those of mercury. Copper also forms a soluble double sulphide, but combines nore readily nce of sodic carbonates. Mercuric sulphide is readily precipitated from these tions than in cold ones, provided that increase of temothers which are less soluble; as happens with sodium chloride, neutral sodium carbonate, etc. Diminishing temperature is thus a cause of precipitation, and di
minishing pressure appears to act in a similar way
There are also other inethods of precipitation which may be carried out under natural conditions. If a na-
tural solution of mercury comes in contact with strong solutions of borax, or with sulphydric acid, or any stronger acid, it will lose a. portion of the mercuric sul-
phide in solution. At Steamboat Springs and Sulphur
Bank large quantities of sulphuric acid are formed near Bank large quantities of sulphuric acid are formed near
the surface, and, percolating down ward, must precipitate mercury in some form. The acid waters penetrate fact that the waters reaching the surface carry so little quicksilver. These same causes must also produce pre-
cipitation of the other ores and of gold from solutions. Another method by which mercuric sulphide may be
precipitated, as has been seen, is mere dilution. Now, precipitated, as has been seen, is mere dilution. Now,
ascending solutions of guicksilver must sonetimes meet with springs; and when they do so, metacinnabarite, or black sulphide, will be precipitated, and with mines a small quantity of "virgin" quicksilver is found and in most it constitutes a very small proportion of the formation of hyposulphite, which actually occurs in of quicksilver with extraneous spring waters thus explains the occurrence of metacinnabarite found in at however, occurs in many mines in which no metacinnasupposition that the metal has been isolated by dilution; for black sulphides in the presence of solutions
of mercury might readily be con verted into the alloof mercury might readily be converted into. the allo-
tropic inodification, and I know of no reason for denyhave been dhe of the cinnabar of the ore deposits may bar and metacinnabarite are sometimes found mixed, as if the conversion to the red form were incomplete; mercuric sulphide is slightly soluble in the waters of
some of the cold mines. some of the cold mines. causa vera of its existence is thus detected, there may
be other ways besides this in which it is produced in nature. Thus sulphydric acid precipitates a mixture of quicksilver and mercuric sulphide from mercurous salts. Whether soluble mercurous salts can occur in
nature, excepting near the earth's surface, is another question. But even light is well known to deconpose
this feeble sulphide, and it is not impossible that the decomposition of organic matter, which is associated in
most cases with cinnabar deposits. and seems to be most cases with cinnabar deposits. and seems to be
specially abundant in the mines in which metallic mercury most prevails, may yield ammonium sulphide and Conclusions. - The conditions of the solution and precipitation of ores traced in this paper appear beyond posits of Steamboat Springs and Sulphur Bank. Most of the other quicksilver mines in California show ores
and gangue minerals of similar composition to these, and gangue minerals of similar composition to these, by warm springs containing much the same salts in considerable a resemblance in many particulars to these deposits as to lead to the belief that they too were
formed by precipitation from solutions of soluble double sulphides.

That pyrite, gold, and other ores are sometimes pro-
uced in nature by other methods is absolutely certain ; doced in nature by other methods is absolutely certain ; from the reduction of iron sulphate by organic matter. tances from the surface; for I know of $n$ dindication of ine formation of iron sulphate far from the oxidizing
ince of the atmosphere. But there may be other solvents yet for these and other minerals which can
form at great depths, and, if such there be, I all convinced they are cases in which they, and not those
which it has been my good fortune to trace in the forewhich it has been my good fortune to trace in the fore-
going pages, have been instrumental in the segregation of ores.
United States Geological Survey, Dec., $18 \dot{86 .}$
-Amer. Jour. of Science.

\section{$\longrightarrow$}

THE MEDICO-LEGAL ASPECTS OF HYPNOTISM.

A. BINET, one of the leading French authorities on nypnotism, has written an appreciative but critical view of the French and Italian standpoints regarding this subject, that is assuming so much importance
there. Dr. Campili has had the advantage of numer-
ous memoirs in France and elsewhere. M. Legeois has shown the possibility of making the hypnotic suggessubject.
MM. Binet and Fere set themselves to determine the conditions under which the reality of the hypnotic suggestion may be admitted by a tribunal-the judicial
proof, in other words. Dr. Campili presents the pro-
blem from the point of view of the two schools of criminologists in Italy, the classical or spiritualistic not only in their theoretical conceptions, but also in ishment. Upon the question of hypnotism, however,
ishe two schools adinit the same conclusion. Dr. Campili examines what the civil and penal responsibility of the hypnotized subject is when criminal acts have under the influence of a hypnotic suggestion. Accord-
ing to the classical legal school, the hypnotized subject is not responsible, since he has not committed a volunment where there has been no fault.
The anthropological school, which does not assume this subjective point of view, but considers that the preservation and defense, arrives at the same conclusion, but by a different way. In a very detailed
discussion the author arrives at the conclusion that the needs of social defense only demund the re- 